\title{
Performance-based provisions for fire safety in the Japanese Building Standard Law: How to connect regulation and engineering
}

\author{
Naohiro Takeichi \\ Office of Design Management Div., General Headquarters, Takenaka Corporation \\ 8-21-1 Ginza, Chuo-ku, Tokyo 104-8182, JAPAN \\ takeichi.naohiro@takenaka.co.jp
}

Ichiro Hagiwara

Fire Standards Div., Building Dept., National Institute for Land and Infrastructure Management

hagiwara-i92hy@nilim.go.jp

Harada Kazunori

Department of Architecture and Environmental Design, Kyoto University

harada@archi.kyoto-u.ac.jp

Makoto Tsujimoto

Graduate School of Environmental Studies, Nagoya University

mtsujimoto@genv.nagoya-u.ac.jp

Wataru Takahashi

ING Co., Ltd.

watachan@hf.catv.ne.jp

\begin{abstract}
In Japan, a performance-based code has been added to the existing Building Standard Law (BSL), rather than making a new Law. Before the revision, performance-based design had been done under the "equivalency" concept. Today, the law itself has been transformed to allow performance-based design. The revision is a result of requests from the legal sector that the Law, rather than the Government, should set standards to rule. As a result, government discretion has become more limited. In order to preserve continuity from the past, the current BSL includes both conventional prescriptive clauses as well as performance-based ones in the evacuation and fire resistant structure sections. The most important point is to clarify the objectives of regulation and their performance criteria. To avoid disturbance of technological development, definite requirements in the BSL and the Enforcement Order have been limited only to functional expressions. To allow efficient implementation, the government has set standard verification methods, new plan review routes and executive bodies. The strategy of verification of fire safety is that each value of prescriptive requirement transfers to the time that is calculated, and performance is required for not only each components of building and their testing method, but also for a unit of the whole floor, or the whole building.
\end{abstract}

KEY WORDS: performance-based code, building control, evacuation safety 
The Building Standard Law (BSL) is the main law that regulates buildings and their equipment. The BSL was established in 1950, and has been amended many times to meet new technologies and to cope with new hazards. As major disasters happened or new technologies were introduced, the government has amended or added new articles that described new requirements and technical specifications. Before 2000, performance based design was done under the equivalency concept. It depended on a provision in the BSL that described the Minister approval for new technologies beyond current expectations. However lawyers criticized the process of approval that was closed to the public because of the applicant's patent, etc, and that the performance criteria depended on the enforcement side. As alternative materials and equipment were already contemplated by each provision, it was also difficult to prove equivalencies that involved multiple provisions that did not include specific objectives and performance criteria. For example, how much smoke exhaust rate is needed to offset an extended travel distance to stairs? The legal sector also worried that the government has an excessive power on the building control. Thus legal sector required "Rule of Law" from "Government by Law." The first one is that law controls government execution in detail; on the other hand the second means the government operates laws.

In 1998 the BSL was revised to include performance-based design, and BSL enforcement order and Notifications described in the performance-based style were established in 2000. Local codes also have been amended to harmonize with them. The equivalency clause was deleted, and the criteria of requirements have been separated from the execution. As a result, discretionary power has become more limited. On the other hand, to clarify the criteria and the role of the government means to increase the responsibility of the owner and the designer, though safety had tended to depend on the enforcement side. As well as technical rationalization, the execution system has also been revised, including plan review \& inspection by a designated private body

Table 1 System of building regulation under the Building Standard Law

\begin{tabular}{lll}
\hline Name of law & Establishing Body & Contents (new provisions) \\
\hline Building Standard Law & National Diet & $\begin{array}{l}\text { Objectives of Law, basic requirements, } \\
\text { authorization, execution system }\end{array}$ \\
\hline $\begin{array}{l}\text { Enforcement order / } \\
\text { Local code }\end{array}$ & $\begin{array}{l}\text { Cabinet / } \\
\text { District Council }\end{array}$ & $\begin{array}{l}\text { Prescriptive requirements, } \\
\text { performance requirements }\end{array}$ \\
\hline Minister of LIT* & $\begin{array}{l}\text { Criteria of requirements for execution: } \\
\text { more detailed prescriptive requirements, } \\
\text { exemplification, verification methods }\end{array}$ \\
\hline Guidelines for execution $^{1}$ & Inspection bodies & $\begin{array}{l}\text { Criteria of requirements for execution: } \\
\text { more detailed prescriptive requirements, } \\
\text { exemplification, testing methods, verification } \\
\text { methods }\end{array}$ \\
\hline
\end{tabular}

*Minister of Land, Infrastructure and Transport ${ }^{2}$

\footnotetext{
${ }^{1}$ In the strict sense, guideline for execution is a public document, rather than a law. However in nature it has enforcement as building regulation.

${ }^{2}$ In a couple of years, the Japanese government has been reforming the administrative structure. As a result, it integrated the former Ministry of Construction and other ministries into the Ministry of Land, Infrastructure and Transport.
} 
The system of building regulation is shown in Table 1. The BSL enforces the requirements throughout Japan. Higher ranking law precedes over lower ranking laws. Higher ranking law is static, more fundamental and lasting long. Lower ranking law describes more detailed requirements and it is relatively easier to be change as technology develops. In order to maintain continuity from past, the BSL retains the conventional prescriptive clause and performance-based clause in parallel. In regard to fire safety, the only revision areas are the sections on evacuation and fire resistant structures (including prevention of fire spread). In this revision, the BSL keeps as same the requirement levels as before, because any new hazard has lead to this revision.

\section{FIRE SAFETY PROVISIONS}

The first step in developing the new performance-based provisions was to categorize the objectives and to find external forces (fire impact) and criteria of safety among provisions in the BSL. The fire safety provisions in the BSL have 5 objectives as shown in Table 2

Table 2 Fire safety objectives and verification methods in the BSL 2000 revision

\begin{tabular}{ll}
\hline \multicolumn{1}{c}{ Objective } & Performance requirements \& verification methods \\
\hline Reduction of fire occurrence & Not provided \\
\hline Evacuation safety & Evacuation safety performance requirement \\
\hline Prevention of collapse & Fire resistant structure \\
\hline Assurance of fire fighting & Not provided \\
\hline Prevention of urban fire & Some parts in fire resistant structure \\
\hline
\end{tabular}

Performance-based requirements are set for two of the above: evacuation safety and prevention of collapse by fire. In the performance-based requirements, depending on level of verification, there are two routes: verification by the Notification, and approval by the Minister. The first one is called Route B, and the second one is called Route C, by contrast the conventional one is called Route A.

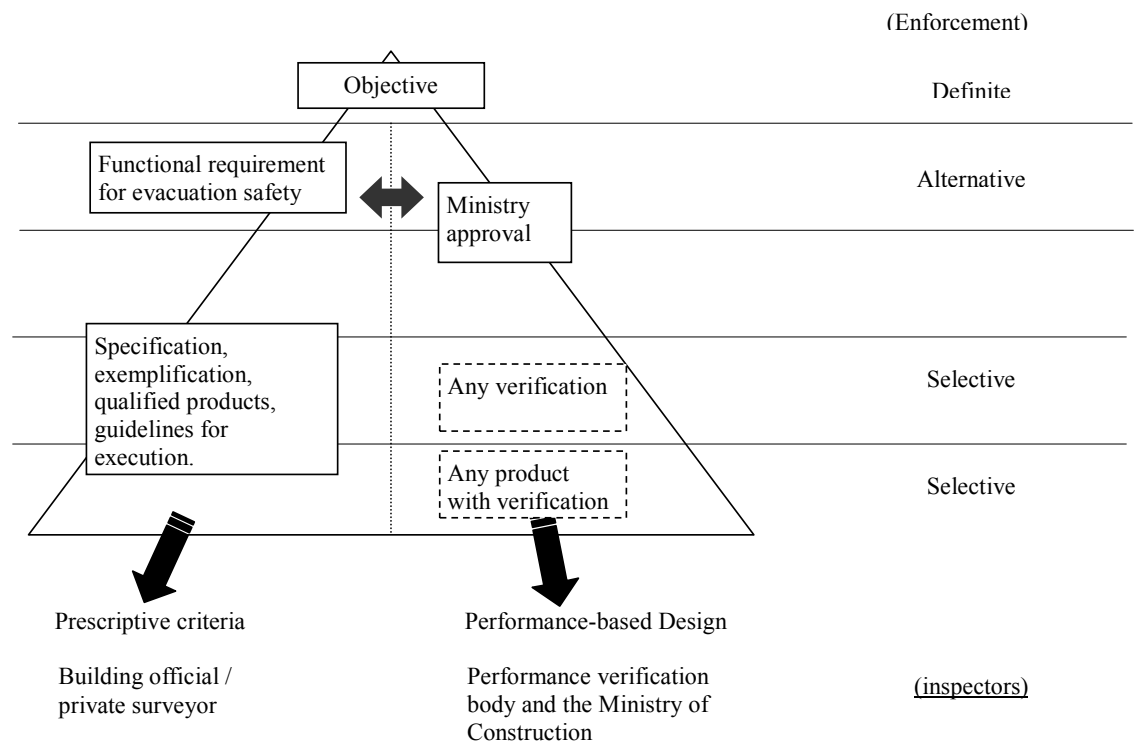

Fig. 1 Structure of technical requirements in the BSL before 2000 (NKB5-Level format) 
(Enforcement)

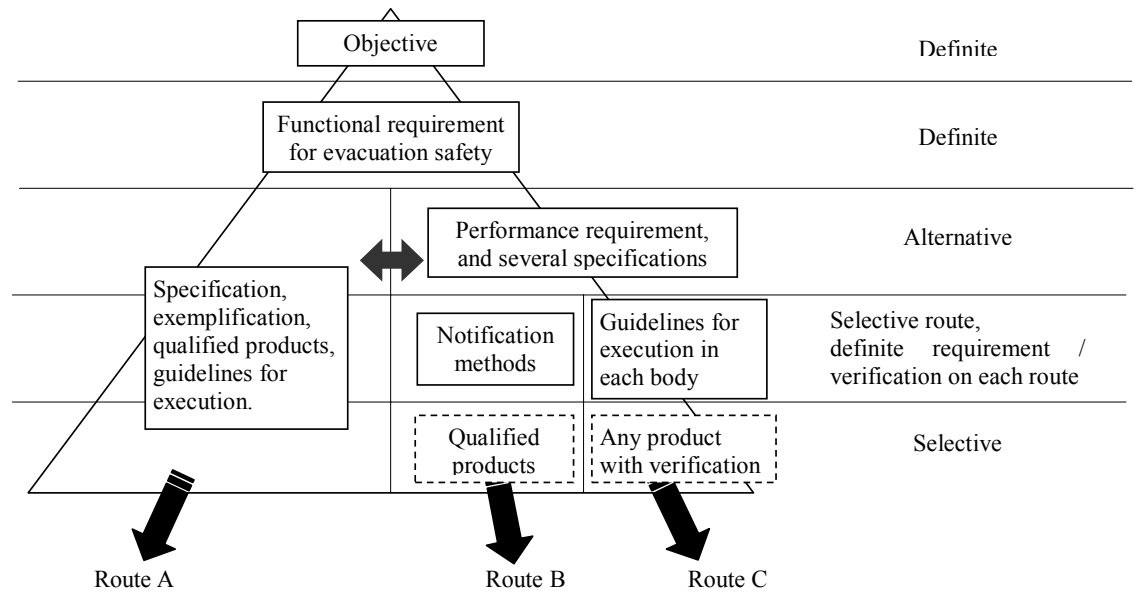

$\begin{array}{llll}\begin{array}{l}\text { Building official } / \\ \text { private surveyor }\end{array} & \begin{array}{l}\text { Building official } / \\ \text { private surveyor }\end{array} & \begin{array}{l}\text { Performance } \\ \text { verification body and } \\ \text { the Ministry of LIT }\end{array} & \end{array}$

Fig. 2 Structure of technical requirements in the BSL after 2000 (NKB5-Level format)

The feature of the plan review by the methods in the Notification on the Route B is to fix the verification methods including input parameters such as fire loads, density of occupants for various use, calculation methods, and criteria. As designers and inspectors cannot modify the verification methods on Route B, the flexibility are limited. However the applicant has a reduced burden and saves time in the plan review process.

The feature of the approval by the Minister is in the freedom to choose verification methods. The Minister judges if the applicant satisfies the functional requirements for evacuation safety. In the approval process, a deputy performance verification body reviews the application. The verification body has a committee composed of authorities to review the submitted plans in accordance with guidelines for execution in each body. The Minister qualifies the performance verification bodies with their own guidelines.

\section{PERFORMANCE CRITERIA FOR PREVENTION OF COLLAPSE BY FIRE}

The prevention of collapse by fire, the fire spread to outside, and catching a fire from fires occurring outside are all required by the BSL. The BSL defines the principal structural members of fireproofed buildings shall either be:

- of fireproof construction, or

- of construction that meets the technical requirements concerning their ability to withstand fire throughout complete process.

The first one is the conventional method that prescribes necessary fireproof ratings of construction. The second one is performance-based. The performance requirement in the enforcement order is described as follows in the article 108-3,

- The following requirements shall be satisfied when exposed to heat generated by a fire foreseeable to take place within the building:

- Bearing walls, columns, floors, beams, roofs and stairs shall not be damaged under 
the stress of fixed and movable loads (in heavy-snow areas, dead load, live load and snow load; hereinafter the same) (non-damage ability requirement).

- Walls and floors shall possess heat insulation property.

- Exterior walls and roofs shall possess flame insulation property.

- Exterior walls shall satisfy the following requirements when exposed to heat caused by fire that normally takes place outside of the building:

- Exterior walls constituting bearing walls shall not be damaged under the stress of dead or live load (non-damage ability requirement).

- Exterior walls shall possess heat insulation property.

\section{PERFORMANCE CRITERIA FOR EVACUATION SAFETY}

In the enforcement order, there are only two performance-based clauses on evacuation:

- Evacuation safety on the fire floor at Article 129-2

- Evacuation safety in the whole building at Article 129-2-2.

These two clauses require the same performance that the smoke and gas resulting from fire in any location shall not block egress routes until all occupants are safely evacuated. These two provisions require the building plan to satisfy the legal performance requirements. They do not judge the safety level quantitatively, but evaluate the degree of satisfaction quantitatively. Article 129-2 only addresses the fire floor, so it cannot evaluate vertical egress routes such as staircases. Article 129-2-2 addresses evacuation of the whole building that requires a more comprehensive verification, including staircases, atria, etc. The functional requirements of evacuation facilities in the articles concentrate on evacuation safety in case of a fire. On the conventional prescriptive clauses, the law requires technical specifications for all equipment, for example, maximum distance to stairs, smoke exhaust volumes. However, for performance criteria, each specification transfers to input parameter for calculations. The revised BSL restricts provisions that are possible to pass over by verification. (See Table 3)

\section{THE NOTIFICATION METHOD AS A STANDARD OF PERFORMANCE VERIFICATION}

On the route of approval by the Minister, it is not mandated to follow the Notification, but the guidelines for execution refer to Notifications in several issues such as fire load and population density. The Notification method on the Route B works as a standard for verification method at present. The Notification method evaluates evacuation safety on calculated time that are the egress time and the time when smoke filling to a critical height for evacuee.

\section{The Notification methods of evacuation safety on the fire floor}

The Notification methods of evacuation safety on the fire floor consist of two parts: Evacuation safety in the fire room and Evacuation safety in the fire floor. The criteria of safety on the Notification methods are show in Table 4.

Verification is required for all the rooms where occupants are normally expected. The applicant has to evaluate and prove safety for all occupants. In the evacuation safety on the fire floor, the applicant also has to evaluate and prove the safety of occupants for a fire starting in any location, including not only normally occupied rooms but also other 
Table 3. Prescriptive provisions and their correspond performance requirements in the BSL enforcement

\begin{tabular}{|c|c|c|c|c|c|c|}
\hline \multirow{2}{*}{ Chap. } & \multirow{2}{*}{\multicolumn{2}{|c|}{ Article. }} & \multirow{2}{*}{ Prescriptive provision } & \multirow{2}{*}{ Treatment in verification method } & \multicolumn{2}{|c|}{$\begin{array}{l}\text { Verification } \\
\text { method }\end{array}$} \\
\hline & & & & & Floor & $\begin{array}{l}\text { Whole } \\
\text { building }\end{array}$ \\
\hline \multirow{5}{*}{ IV } & \multirow{5}{*}{112} & $1-4$ & Fire compartment in general & No treatment & - & - \\
\hline & & $5-7$ & Fire compartment over $11^{\text {th }}$ floor & Parameter of smoke movement & - & $\checkmark$ \\
\hline & & 9 & $\begin{array}{l}\text { Fire compartment of room through some } \\
\text { stories, like atrium, EV shaft, etc }\end{array}$ & Parameter of smoke movement & - & $\checkmark$ \\
\hline & & 10,11 & $\begin{array}{l}\text { Treatment on outside wall of fire } \\
\text { compartment }\end{array}$ & No treatment & - & - \\
\hline & & 12,13 & Fire compartment among different uses & Parameter of smoke movement & - & $\checkmark$ \\
\hline \multirow{33}{*}{$\mathrm{V}$} & $116-2,117$ & & Habitable room with no openings, etc & $\begin{array}{lll}\begin{array}{l}\text { Coverage of requirement for } \\
\text { evacuation safety }\end{array} & & \\
\end{array}$ & & \\
\hline & 118 & & $\begin{array}{l}\text { Requirement for exits to open in the } \\
\text { direction of movement from audience halls }\end{array}$ & No treatment & - & - \\
\hline & 119 & & Width of corridors & Parameter of flow rate of egress & $\checkmark$ & $\checkmark$ \\
\hline & 120 & $1-4$ & Distance limitation to direct stairs & Parameter of egress & $\checkmark$ & $\checkmark$ \\
\hline & \multirow{2}{*}{121} & $1-2$ & Necessity of two or more direct stairs & No treatment & - & - \\
\hline & & 3 & Limit of overlapped way to another stairs & No treatment & & \\
\hline & $121-2$ & & Prohibition of wooden outside stairs & No treatment & - & - \\
\hline & \multirow{2}{*}{122} & 1 & Emergency stairs for stories & No treatment & - & - \\
\hline & & 2,3 & Emergency stairs for stores & No treatment & - & - \\
\hline & \multirow{9}{*}{123} & & Construction of emergency stairs & $(2)-(5),(7)$ : no treatment & - & - \\
\hline & & 1 & $\begin{array}{l}\text { (1) Construction of emergency stairs } \\
\text { (6) Fire door of emergency stairs }\end{array}$ & Parameter of smoke movement & - & $\checkmark$ \\
\hline & & \multirow{2}{*}{2} & Construction of outside emergency stairs & (1), (3): no treatment & - & - \\
\hline & & & (2) Fire door of emergency stairs & Parameter of smoke movement & - & $\checkmark$ \\
\hline & & \multirow{5}{*}{3} & Construction of special emergency stairs & $(3)-(8),(10):$ no treatment & & \\
\hline & & & (1) Requirement of attached room & Parameter of smoke movement & $\checkmark$ & $\checkmark$ \\
\hline & & & (2) Construction & Parameter of smoke movement & - & $\checkmark$ \\
\hline & & & (9) Fire door & Parameter of smoke movement & $\checkmark$ & $\checkmark$ \\
\hline & & & (11) Area requirement of attached room & Parameter of flow rate of egress & $\checkmark$ & $\checkmark$ \\
\hline & $123-2$ & & Regarding dwelling houses & Parameter of egress & $\checkmark$ & $\checkmark$ \\
\hline & \multirow{4}{*}{124} & & (1) Width of emergency stairs for stores & Parameter of flow rate of egress & - & $\checkmark$ \\
\hline & & 1 & $\begin{array}{l}\text { (2) Width of exit to emergency stairs for } \\
\text { stores }\end{array}$ & Parameter of flow rate of egress & $\checkmark$ & $\checkmark$ \\
\hline & & 2 & Exception under $2^{\text {nd }}$ floor & Parameter of egress & $\checkmark$ & $\checkmark$ \\
\hline & & 3 & Treatment of open space on roof & Treatment as floor & $\checkmark$ & $\checkmark$ \\
\hline & \multirow{4}{*}{125} & 1 & Distance to exits to outside & Parameter of egress & - & $\checkmark$ \\
\hline & & 2 & $\begin{array}{l}\text { Requirement for exits to outside to open in } \\
\text { the direction of movement for use of } \\
\text { audience hall }\end{array}$ & No treatment & - & - \\
\hline & & 3 & Width of exit to outside for stores & Parameter of flow rate of egress & - & $\checkmark$ \\
\hline & & 4 & Treatment of open space on roof & Treatment as floor & $\checkmark$ & $\checkmark$ \\
\hline & $125-2$ & 1,2 & Construction of locks at exit & No treatment & - & - \\
\hline & 126 & 1,2 & Open space on roof & No treatment & - & - \\
\hline & $126-2$ & & Installation of smoke exhaust equipment & Parameter of smoke exhaust & $\checkmark$ & $\checkmark$ \\
\hline & $126-3$ & & Construction of smoke exhaust equipment & Parameter of smoke exhaust & $\checkmark$ & $\checkmark$ \\
\hline & $126-4,126-5$ & & Emergency lighting equipment & Matter of assurance of fire fighting & - & - \\
\hline & $\begin{array}{ll}126-6, & 126- \\
7,127, & 128 \\
128-2 & \end{array}$ & & $\begin{array}{l}\text { Entrance for emergency use, Passage within } \\
\text { building site }\end{array}$ & Matter of assurance of fire fighting & & \\
\hline \multirow{8}{*}{$\mathrm{V}-2$} & \begin{tabular}{|l|}
$128-3-2$ \\
$128-4$ \\
\end{tabular} & & Habitable room with no openings, etc & $\begin{array}{l}\text { Coverage of restriction for interior } \\
\text { finish }\end{array}$ & & \\
\hline & \multirow{7}{*}{129} & 1 & Interior finish depending on uses, etc & Parameter of smoke produced & $\checkmark$ & $\checkmark$ \\
\hline & & 2 & Interior finish of garage, auto-repair shops & Matter of reduction of fire occurrence & - & - \\
\hline & & 3 & Interior finish of rooms on the basement & Parameter of smoke produced & $\checkmark$ & $\checkmark$ \\
\hline & & 4 & Interior finish depending on stories and scale & Parameter of smoke produced & $\checkmark$ & $\checkmark$ \\
\hline & & 5 & $\begin{array}{l}\text { Interior finish in the habitable room with no } \\
\text { openings }\end{array}$ & Parameter of smoke production & $\checkmark$ & $\checkmark$ \\
\hline & & 6 & Interior finish in kitchen & Matter of reduction of fire occurrence & - & - \\
\hline & & 7 & Exception of restriction with sprinkler & No treatment & - & - \\
\hline \multirow{2}{*}{$\mathrm{V}-2-2$} & $129-2$ & & evacuation safety on the fire floor & Functional statements & $\checkmark$ & \\
\hline & $129-2-2$ & & Evacuation safety in the whole building & Functional statements & & $\checkmark$ \\
\hline
\end{tabular}


rooms such as storage.

Table 4 Criteria of evacuation safety on the Notification methods

\begin{tabular}{ll}
\hline Verification methods & Criteria of evacuation safety \\
\hline $\begin{array}{l}\text { The fire room } \\
\text { The fire floor }\end{array}$ & All evacuees can escape to exits before the smoke filling to $1.8 \mathrm{~m}$ \\
\hline The whole building & $\begin{array}{l}\text { All evacuees can escape to the outside before the smoke flows into } \\
\text { staircases, upper floors, atrium, EV shaft etc. }\end{array}$ \\
\hline
\end{tabular}

The Notification method calculates two kinds of time.

- Egress time $\left(t_{e}\right)$

- Time that smoke fills to a critical height for an evacuee $\left(t_{s}\right)$

To compare these times, the evacuation safety is judged by,

$$
t_{e}<t_{s},
$$

$t_{e}$ consists of 3 components and it is sum of the three,

$$
t_{e}=t_{\text {start }}+t_{\text {travel }}+t_{\text {queue }},
$$

where $t_{\text {start }}$ is the time from the outbreak of fire until the start of evacuation, $t_{\text {travel }}$ is the walking time to exits and $t_{\text {queue }}$ is the queuing time in front of the exit doors.

Meanwhile, the time to smoke filling to a critical height for evacuee $\left(t_{s}\right)$ is given by,

$$
t_{s}=\frac{A_{\text {room }} \times\left(H_{\text {room }}-H_{\text {lim }}\right)}{V_{s}-V_{e}},
$$

where $A_{\text {room }}\left(\mathrm{m}^{2}\right)$ is the area of the room, $H_{\text {room }}(\mathrm{m})$ is the ceiling height of the room, $H_{\text {lim }}$ (m) is the critical smoke layer height for evacuation. About the Notification method, $H_{\text {lim }}$ of the fire room evacuation is $1.8 \mathrm{~m}$. $H_{\text {lim }}$ of fire floor evacuation or whole building evacuation is set to the height critical to smoke spread to the adjoining space through wall openings. $A_{\text {room }} \times\left(H_{\text {room }}-H_{\text {lim }}\right)$ means the reservoir volume for smoke in the room. $V_{s}\left(\mathrm{~m}^{3} / \mathrm{min}\right)$ is the smoke production rate, and $V_{e}\left(\mathrm{~m}^{3} / \mathrm{min}\right)$ is smoke exhaust rate.

On the Notification methods, the criterion of evacuation safety is determined by smoke filling. Other criteria including smoke temperature, flashover of interior finish and so on are considered when predicting fire growth and smoke production.

\section{The verification method in the fire room}

Theoretically the starting time includes detection of fire, information transfer and reaction of occupants. In the Notification method the start time is calculated from the room area. The time to start evacuation in the room of fire origin is calculated by,

$$
t_{\text {start }}=\frac{\sqrt{A_{\text {room }}}}{30},
$$

where $A_{\text {room }}\left(\mathrm{m}^{2}\right)$ is a measure of the room area. 
The walking time is given by,

$$
t_{\text {travel }}=\sum \frac{l}{v}
$$

where $l(\mathrm{~m})$ is the walking distance from the furthest point to the exit in the room and $v$ $(\mathrm{m} / \mathrm{min})$ is the walking velocity. The velocity values account for characteristics of occupants (familiar or non-familiar), and direction of movement (flat, up/ downstairs).

The queuing time is calculated by the next formula.

$$
t_{\text {queue }}=\frac{\sum p A_{\text {room }}}{\sum N_{\text {eff }} B_{\text {eff }}},
$$

where $p$ (persons $/ \mathrm{m}^{2}$ ) is the occupant density that is related to its use. $\sum p A_{\text {room }}$ is the body count inside the area. The specific flow rate $N_{\text {eff }}$ (persons $/ \mathrm{m}^{2} / \mathrm{min}$ ) is related to the condition of the adjoining spaces. If the next space is expected to be crowded and then evacuee cannot move to it smoothly, $N_{\text {eff }}$ is reduced. (Figure 4) $B_{\text {eff }}$ is an available exit door width that takes account the possibility of door blockage by fire occurrence close to the widest exit. (Figure 5)

On the other hand, in the calculation of $t_{s}$ when smoke fills to a critical height for evacuees in accordance with formula (3), the smoke production rate $V_{s}$ that is produced is calculated by the next formula,

$$
V_{s}=9\left\{\left(\alpha_{f}+\alpha_{m}\right) A_{\text {room }}\right\}^{\frac{1}{3}}\left(H_{\text {room }}^{\frac{5}{3}}+H_{\lim }^{\frac{5}{3}}\right),
$$

where $\alpha_{f}\left(\mathrm{~kW} / \mathrm{s}^{2}\right)$ is the fire growth rate calculated by fuel arrangement including furniture, papers and so on. The fire origin in the formula uses the concept that heat release rate is related to time squared. For simplicity, $\alpha_{f}$ can be calculated by a fire load density. $\quad \alpha_{m}\left(\mathrm{~kW} / \mathrm{s}^{2}\right)$ is related to fire growth over interior finish.

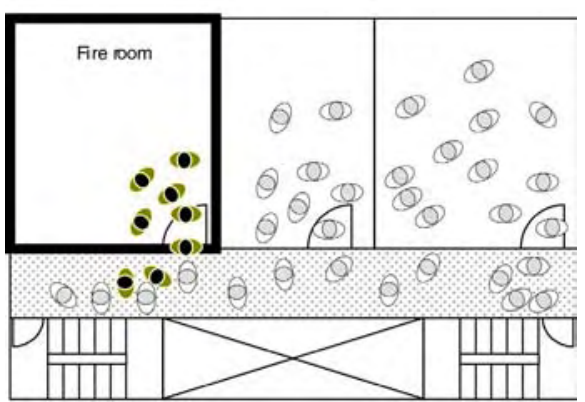

Figure 4. $\quad N_{\text {eff }}$ that counts the adjoining space condition

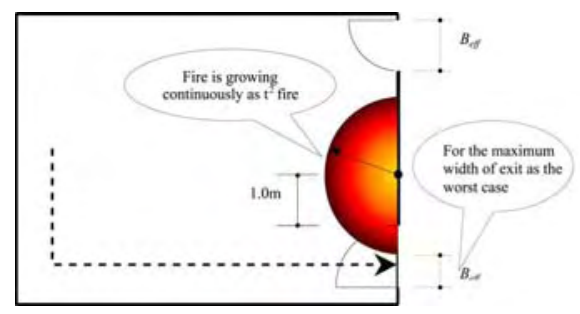

Figure 5. $B_{\text {eff }}$ that counts fire growth 
The net volume of smoke exhaust ventilation is calculated by the formula below.

$$
V_{e}=\min \left(A^{*} \times E\right)
$$

where $A^{*}$ is the efficiency of smoke exhaust with smoke curtains, $E\left(\mathrm{~m}^{3} / \mathrm{min}\right)$ is the capability of smoke exhaust.

$E$ is calculated according to the type of smoke exhaust system: mechanical smoke exhaust, smoke exhaust through a window, and pressurizing system, as shown in Table 5.

\section{The verification method for the fire floor evacuation}

The format of verification is same as the fire room verification. On the floor, $t_{e}$ is given by the following formula,

$$
t_{e}=t_{\text {start }}+\sum \frac{l}{v}+\frac{\sum p A_{\text {area }}}{\sum N_{\text {eff }} B_{\text {st }}},
$$

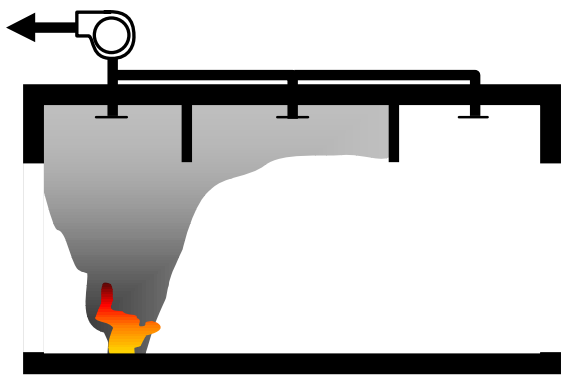

Smoke curtains to make smoke layer

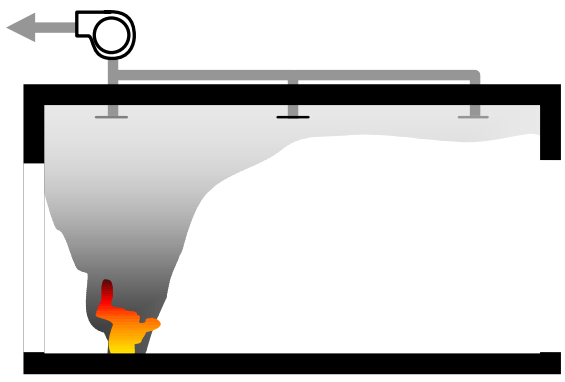

No smoke curtains

Figure 6. $A *$ that take count of an efficiency of smoke curtains

Table 5 Smoke exhaust rate

\begin{tabular}{lc}
\hline Smoke exhaust system & Smoke exhaust rate $\left(\mathrm{m}^{3} / \mathrm{min}\right)$ \\
\hline mechanical smoke exhaustion & $E=\min \left[\sum \min \left\{w, 3.9\left(H_{c}-1.8\right) w^{\frac{2}{3}}\right\}\right]$ \\
smoke exhaust window & $E=\min \left[\sum \max \left\{19 A_{s} \sqrt{\left.\left.h_{s}, \frac{76 A_{s} \sqrt{H_{c}-1.8}}{\sqrt{\sum_{A_{s}}}}\right\}\right]}\right]\right.$
\end{tabular}

pressurizing system

$$
E=\min \left(s, 550 A_{s}\right)
$$

no smoke exhaust equipment $\quad E=0$

where $H_{c}(\mathrm{~m})$ is the height of vent above floor. $w\left(\mathrm{~m}^{3} / \mathrm{min}\right)$ is the air volume rate of mechanical exhaust system. $A_{s}\left(\mathrm{~m}^{2}\right)$ is the area of smoke exhaust through the window. $h_{s}(\mathrm{~m})$ is the height of the window. $A_{a}\left(\mathrm{~m}^{2}\right)$ is the area of air supply openings. $s\left(\mathrm{~m}^{3} / \mathrm{min}\right)$ is air volume rate used for pressurization. 
where $A_{\text {area }}\left(\mathrm{m}^{2}\right)$ is area of each room, $B_{s t}$ is the width of exit to stairs.

The time to start evacuation is calculated depending on the rooms where occupants are expected to sleep, as shown in Table 6

Table 6 Time to start evacuation on the Notification method on the fire floor Use of building Time to start evacuation ( $\mathrm{min})$

\begin{tabular}{cc}
\hline Apartment, dormitory, hotel & $t_{\text {start }}=\frac{\sqrt{A_{\text {floor }}}}{30}+5$ \\
\hline Others & $t_{\text {start }}=\frac{\sqrt{A_{\text {floor }}}}{30}+3$ \\
\hline
\end{tabular}

where $A_{\text {floor }}\left(\mathrm{m}^{2}\right)$ is s measure of the floor area.

The time to smoke filling $t_{s}$ for fire floor verification is the time when smoke fills to the critical height in front of the exit door of emergency staircases. On a floor, there are many rooms where fire might occur and many routes that smoke can spread to the staircase. Because of that, it is necessary to calculate all cases. At first a fire room is selected. Then the route of smoke spread to staircases and rooms on the route are identified. For all the combinations of fire origin and smoke spread routes, $t_{s}$ is calculated. Finally $t_{s}$ of the fire floor is the minimum value of calculated $t_{s}$ in any case.

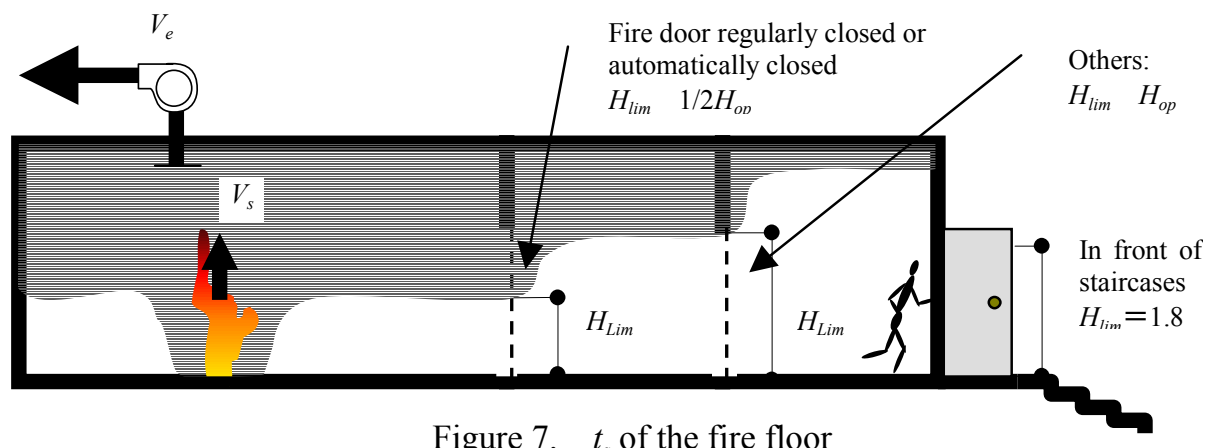

$$
t_{s} \text { on the floor }=\sum t_{s} \text { of each room }=\sum \frac{A_{\text {room }} \times\left(H_{\text {room }}-H_{\text {lim }}\right)}{V_{s}-V_{e}},
$$

where $H_{\text {lim }}$ is the critical height for evacuee or the height that smoke spreads to adjoining space. $H_{\text {lim }}$ is reflected to the structure of walls and openings of the room. As the opening is the fire door, $H_{\text {lim }}$ is defined $1 / 2$ of the height of opening, neither $H_{\text {lim }}$ is whole height of opening.

The smoke leak rate, $V_{s}$ to adjacent room is calculated in accordance with constructions of separating walls and openings, as shown in Table 7

\section{The Verification method in the whole building}

The format of verification is same as the for fire room verification below, 
Table 7. $V_{s}$ in non-fire room

\begin{tabular}{ll}
\hline \multicolumn{1}{c}{ Structure of walls and openings } & $V_{s}\left(\mathrm{~m}^{3} / \mathrm{min}\right)$ \\
\hline $\begin{array}{l}\text { Semi-fire resistant walls or covered non-combustible materials and fire } \\
\text { door which has smoke insulation }\end{array}$ & $V_{s}=0.2 A_{o p}$ \\
\hline $\begin{array}{l}\text { Semi-fire resistant walls or covered non-combustible materials, fire } \\
\text { door with smoke insulation and pressurizing system is used }\end{array}$ & $V_{s}=0.2 A_{o p}$ \\
\hline $\begin{array}{l}\text { Semi-fire resistant walls or covered non-combustible materials and fire } \\
\text { stop door }\end{array}$ & $V_{s}=2 A_{o p}$ \\
\hline Others & $V_{s}=\max \left(V_{s 0}-V_{e}\right)$ \\
\hline
\end{tabular}

$V_{s}\left(\mathrm{~m}^{3} / \mathrm{min}\right)$ is the leak rate from the fire room, $A_{o p}\left(\mathrm{~m}^{2}\right)$ is sum of all opening area between the fire room and the room, $V_{s 0}\left(\mathrm{~m}^{3} / \mathrm{min}\right)$ is the produced smoke volume in the fire room, $V_{e}$ $\left(\mathrm{m}^{3} / \mathrm{min}\right)$ is natural smoke ventilation volume in the fire room.

$$
t_{e}=t_{\text {start }}+\sum \frac{l}{v}+\frac{\sum p A_{\text {room }}}{\sum N_{\text {eff }} B_{d}},
$$

where $A_{\text {room }}\left(\mathrm{m}^{2}\right)$ is area of each room, $B_{d}$ is the width of exits to outside.

The time to start evacuation is also changed whether it has beds or not. (Table 8)

Table 8. The start time on the Notification method in the whole building Use of building Time to start evacuation ( $\mathrm{min})$

\begin{tabular}{cc} 
Use of building & Time to start evacuation (min) \\
\hline Apartment, dormitory, hotel & $t_{\text {start }}=\frac{2 \sqrt{A_{\text {floor }}}}{15}+5$ \\
\hline Others & $t_{\text {start }}=\frac{2 \sqrt{A_{\text {floor }}}}{15}+3$ \\
\hline
\end{tabular}

where $A_{\text {floor }}\left(\mathrm{m}^{2}\right)$ is a measure of the fire floor area.

On the whole building verification, the evacuation limit time is calculated as the time to the smoke spreads to any of the vertical shafts including staircase, atrium, EV shaft, etc. $t_{s}$ of the whole building is also the sum of the $t_{s}$ of each room on the way from the fire to the end. The whole building evacuation safety also requires the $t_{s}$ for any fire not exceed its $t_{e}$.

\section{THE APPROVAL BY MINISTER}

The Notification methods may fix technologies, because every verification addresses a certain technology. The approval by Minister does not fix any verification method. It is intended to be used in complicated cases like a hospital that has handicapped people or new technology without verification in the Notification method. The applicant proves that smoke shall not hinder egress until all occupants are safely evacuated based on the Article 129-2 or the Article 129-2-2 in any verification method. In the process, the performance verification body reviews the application on the guideline of execution that is approved by the Minister. As a general rule, most guidelines refer input values like fire loads to corresponding values in the Notification methods. Of course, an applicant can set his/her own values if he/she has to prove its rationale. Generally, The format of verification uses time comparison concept. Building Center of Japan (BCJ), which is an 
approved performance verification body, evaluates the evacuation limit time in consideration of the various factors that impact human safety, including smoke layer height, temperature, and concentration, smoke spread conditions, the efficiency of smoke exhaust, etc. BCJ also considers all the various factors together about the egress.

\section{CONCLUSIONS}

On the legal side, this revision means how to execute the building control, other words how to control execution sector. On the other side including designer, engineer, and developer, the revision means how to keep flexibility for technological development. For "Rule of Law", the fire safety objectives and functional requirements in the BSL, those had been unspecified in prescriptive clauses, have been clarified, as well as the methods, criteria and external forces used in the performance verification. These criteria are also separated from the execution side. The verification uses the concept of the calculated time comparison. In the system of building regulation, to avoid requirements that restrict technological development, only functional and qualitative requirements are definite, and the designer chooses physical performance values or verification methods. In the actual approval process, several routes are prepared depending on level of technologies. Designers can select more effective actions to use the verifications, and the industry can develop new technology under the system.

\section{REFERENCES}

[1] Tsujimoto, M., Hagiwara, I., Harada, K., Takahashi, W., Takeichi, N., "Performance Evaluation Methods for Fire Safety Issues in the Building Standards Law of Japan", Bulletin of the Japan association for Fire Science and Engineering, Vol. 49 (1), pp. 7-15, (in Japanese), 1999

[2] Shuichi Yusa, Makoto Tsujimoto, "Progress and Overview of Performance-based Codes and Standards in Japan", $15^{\text {th }}$ US-Japan on Natural Resources Panel on Fire Research and Safety, Vol.1, pp169-174, March 2000

[3] Shuichi Yusa, Makoto Tsujimoto, "Outline of Reforming The Building Standards Law in Japan", $15^{\text {th }}$ US-Japan on Natural Resources Panel on Fire Research and Safety, Vol.1, pp181-187, March 2000

[4] Ichiro Hagiwara, "Evaluation Method of Egress Safety", 15 ${ }^{\text {th }}$ US-Japan on Natural Resources Panel on Fire Research and Safety, Vol.1, pp161-165, March 2000

[5] Harada, K., Takeichi, N., Sekizawa, A., "Performance Evaluation Methods for Evacuation Safety and for Structural Fire Resistance" Proceeding $3^{\text {rd }}$ Int. Conf. on Performance-Based Codes and Fire Safety Design Methods, pp.212-223, 2000

[6] Building Guidance Div., Housing Bureau, Minister of LIT, BRI, Japan Conference of Building Officials, Building Center of Japan, "Introduction of the Evacuation Safety Verification Method and its Examples -2001edition", the workshop textbook by Building Center of Japan, Inoue Shoin, (in Japanese), 2001

[7] Building Guidance Div., Housing Bureau, The Ministry of Construction, "Introduction of the revised Building Standard Law (enforcement in 2year's time) 1998.6.1 edition", the workshop textbook by Building Center of Japan, Shin Nihon Houki, (in Japanese), 2000

[8] Naohiro Takeichi, "Approach to Efficient System of Building Control", $15^{\text {th }}$ USJapan on Natural Resources Panel on Fire Research and Safety, Vol.1, pp222-227, March 2000 